\title{
Prevalence and risk factors of diabetes in a large community-based study in North India: results from a STEPS survey in Punjab, India
}

\author{
Jaya Prasad Tripathy ${ }^{1}$, J. S. Thakur ${ }^{2 *}$, Gursimer Jeet ${ }^{2}$, Sohan Chawla ${ }^{2}$, Sanjay Jain ${ }^{3}$, Arnab Pal ${ }^{4}$, Rajendra Prasad ${ }^{4}$
} and Rajiv Saran ${ }^{5}$

\begin{abstract}
Aims: India is the diabetes capital with home to 69.1 million people with DM, the second highest number of cases after China. Recent epidemiological evidence indicates a rising DM epidemic across all classes, both affluent and the poor in India. This article reports on the prevalence of diabetes and pre-diabetes in the North Indian state of Punjab as part of a large household NCD Risk Factor Survey.

Methods: A household NCD STEPS survey was done in the state of Punjab, India in a multistage stratified sample of 5127 individuals. All the subjects were administered the WHO STEPS questionnaire, anthropometric and blood pressure measurements. Every alternate respondent in the sample $(n=2499)$ was assayed for blood parameters.

Results: Overall prevalence of DM among the study participants was found out to be $8.3 \%$ (95\% Cl 7.3-9.4\%) whereas prevalence of prediabetes was 6.3\% (5.4-7.3\%). Age group (45-69 years), marital status, hypertension, obesity and family history of DM were found to be the risk factors significantly associated with DM. Out of all persons with DM, only $18 \%$ were known case of DM or on treatment, among whom only about one-third had controlled blood glucose status.

Conclusions: The study reported high prevalence of diabetes, especially of undiagnosed cases amongst the adult population, most of whom have uncontrolled blood sugar levels. This indicates the need for systematic screening and awareness program to identify the undiagnosed cases in the community and offer early treatment and regular follow up.
\end{abstract}

Keywords: Diabetes, Epidemiology, STEPS survey

\section{Background}

According to International Diabetes Federation estimates, around 415 million people had DM in 2015 and this number is expected to rise to 642 million by 2040 [1]. Around $75 \%$ of subjects with DM live in low- and middleincome countries (LMICs). In financial terms, the global burden of DM is enormous, with an estimated annual

\footnotetext{
*Correspondence: jsthakur64@gmail.com

${ }^{2}$ School of Public Health, Post Graduate Institute of Medical Education and Research, Chandigarh, India

Full list of author information is available at the end of the article
}

expenditure of 673 billion US dollars in 2015, which constituted $12 \%$ of global health spending for that year [1]. While in urban areas of LMICs, diabetes is well recognized as a public health priority; recent prevalence data suggest that diabetes is an increasing problem among rural populations as well [2].

India is home to 69.1 million people with DM and is estimated to have the second highest number of cases of DM in the world after China in 2015 [1]. The prevalence of DM in India ranges from $5-17 \%$, with higher levels found in the southern part of the country and in urban areas [3-9]. DM continues to increase as a result of 
rapid cultural and social changes, which include: ageing populations, increasing urbanization, dietary changes, reduced physical activity and unhealthy behavior. Historically a disease of the affluent, recent epidemiological evidence indicates a rising DM incidence and prevalence in urban India's middle class and working poor [10]. Indians are also believed to have a greater degree of insulin resistance and a stronger genetic predisposition to diabetes [11].

Against this background, an understanding of the changing epidemiology of diabetes in India is required. Estimation of the prevalence of diabetes and identification of high risk groups is essential for planning of community based risk factor reduction interventions. There is currently insufficient information available on prevalence of type 2 diabetes and associated factors in North India. Previous community based studies in this region have been limited only to the Union Territory of Chandigarh which does not truly represent the North Indian population [3, 9]. Using a large cross-sectional data of 2700 individuals drawn from a multistage stratified sample in a North Indian state of Punjab, this study assesses the prevalence of type $2 \mathrm{DM}$ and its associated risk factors (socio-demographic and behavioural).

\section{Methods}

\section{Study design}

This study reports results of a cross-sectional survey conducted in the state of Punjab, India using a multistage stratified sample.

\section{Study setting}

Punjab is a prosperous state in northern part of India bordering Pakistan with a population of 27 million according to 2011 national census. It ranks second in terms of human development index among all states [12]. A state wide non communicable disease (NCD) risk factor survey based on WHO-STEPS approach was undertaken in Punjab in 2014-2015. The survey adopted a multistage stratified, geographically clustered sampling approach using the 2011 census sampling frame. A three-stage design was employed in urban areas whereas in rural areas a two-stage sampling design was followed. Out of a total of 100 Primary Sampling Units (PSUs), there were 60 villages from rural areas and 40 Census Enumeration Blocks from the urban locality. From each selected PSU, 54 households were selected using systematic random sampling. The ultimate sampling units were the households and one individual in the age group of 18-69 years residing in the selected household was selected using the KISH method. The details of the methodology can be found in another paper [13].

\section{Data collection instrument}

A culturally adapted, Punjabi (local language) translated and pre-tested version of the WHO STEP Surveillance (STEPS) questionnaire (version 3.1) was used with minor adaptations [14]. As part of the household survey, socio demographic and behavioural information on tobacco and alcohol use, diet, physical activity, history of chronic diseases, family history of chronic conditions, health screening, and health care costs were collected in Step 1. Physical measurements such as height, weight, blood pressure and waist circumference were collected in Step 2. Biochemical tests were conducted to measure fasting blood glucose, total cholesterol, triglycerides, HDL and LDL cholesterol in Step 3.

\section{Data collection}

Data were collected by trained investigators. SECA adult portable stadiometer was used to measure height after removing shoes, socks, slippers and any head gear. It was measured in centimetres up to $0.1 \mathrm{~cm}$. SECA digital weighing scale was used to measure weight of the individuals. The scale was regularly calibrated against a standard weight. The participants were asked to remove footwear and socks and weight was recorded in kilograms up to $0.1 \mathrm{~kg}$. Waist circumference was measured using a SECA constant tension tape to the nearest $0.1 \mathrm{~cm}$ at the level of the midpoint between the inferior margin of the last rib and the iliac crest in the mid-axillary plane. The measurement was taken at the end of a normal expiration with the arms relaxed at the sides.

One serving of vegetable was considered to be one cup of raw green leafy vegetables or $1 / 2$ cup of other vegetables (cooked or chopped raw). One serving of fruit was considered to be one medium size piece of apple, banana or orange, $1 / 2$ cup of chopped, canned fruit or $1 / 2$ cup of fruit juice.

Physical activity was assessed using the Global Physical Activity Questionnaire (GPAQ), which has been developed by the World Health Organization and used in the STEPS questionnaire. This questionnaire assesses physical activity behaviour in three different domains: work, transport and during leisure time. Activities are classified into three intensity levels: vigorous, moderate and light. 'Vigorous-intensity activities' are activities that require hard physical effort and cause large increases in breathing or heart rate, 'moderate-intensity activities' are activities that require moderate physical effort and cause small increases in breathing or heart rate. Participants were classified as sufficiently active who exceed the minimum duration of physical activity per week recommended by WHO i.e. $150 \mathrm{~min}$ of moderate intensity physical activity or $75 \mathrm{~min}$ of vigorous intensity physical activity or 
an equivalent combination of moderate- and vigorousintensity physical activity achieving at least 600 METminutes per week with each activity performed in bouts of at least 10-min duration [15]. Obesity was defined as BMI $\geq 27.5$. Show cards (pictorial, adapted to the local context) were used to explain to the participants the type of physical activity, servings of fruits and vegetables and salty food intake.

Biochemical measurements (step 3): Every alternate individual (50\%) of the initial sample was subjected to steps 3 (around 2700). A mix of dry and wet chemistry methods was used to assess biochemical profile of participants using blood and urine samples. For blood glucose, dry chemistry method was used by blood glucose measurement device (Optium H, Freestyle). For lipid profile i.e. cholesterol and triglycerides measurements, blood samples were drawn on individuals after 10-12 h fasting. $5 \mathrm{ml}$ of venous blood was taken in sitting position, and centrifuged immediately to separate serum, and transferred under cold chain condition to the Central Reference Laboratory of Department of Biochemistry, Post Graduate Institute of Medical Education and Research, Chandigarh, India.

Laboratory measurement of triglyceride was made on Modular P 800 autoanalyzer (Roche Diagnostics, Germany) using commercially available kits (Roche Diagnostics, Germany).

\section{Sample size}

Sample size of 4609 was calculated using the estimated prevalence of physical activity as 50\%, 0.05 margin of error and $95 \%$ confidence interval. Assuming a response rate of $85 \%$, sample size was raised to 5400 . Every 2nd individual was subjected to Step 3 i.e. biochemical assessment. Out of 2700 respondents, 2499 (93\%) gave consent to blood sampling for biochemical assessment.

\section{Data analysis}

Categorical variables are summarized using proportions and continuous variables using mean or median, whichever is applicable, with $95 \%$ confidence intervals. Chi square test was used for comparison of proportions across groups and ANOVA test for comparison of means across groups. Univariate and multiple logistic regression analysis (backward conditional method) was done to determine the predictors of diabetes. Variables entered into the multiple regression models were selected on the basis of significance $(p<0.2)$ in the univariate analysis. Statistical analysis was done using SPSS version 16.0.

The Institute Ethics Committee of Post Graduate Institute of Medical Education and Research, Chandigarh approved the study (reference number P-727, dated July
21, 2014). Informed written consent was taken from all participants.

\section{Operational definitions \\ Dyslipidemia}

National Cholesterol Education Programme (NCEP) guidelines [10] were used for definition of dyslipidemia as follows:

\section{Hypertriglyceridemia - serum triglyceride levels $\geq 150 \mathrm{mg} / \mathrm{dl}$} $(\geq 1.7 \mathrm{mmol} / \mathrm{l})$.

\section{Diabetes}

Individuals diagnosed by a physician and/or on antidiabetic medications and/or those who had fasting blood glucose $\geq 126 \mathrm{mg} / \mathrm{dl}(\geq 7 \mathrm{mmol} / \mathrm{l})[16]$.

\section{Prediabetes or impaired fasting glucose [IFG]}

Two different cut-offs have been used: Fasting blood glucose $\geq 100 \mathrm{mg} / \mathrm{dl}(\geq 5.6 \mathrm{mmol} / \mathrm{l})$ and $<126 \mathrm{mg} / \mathrm{dl}$ $(<7 \mathrm{mmol} / \mathrm{l})$ [16] and fasting blood glucose $\geq 110 \mathrm{mg} / \mathrm{dl}$ $(\geq 6.1 \mathrm{mmol} / \mathrm{l})$ and $<126 \mathrm{mg} / \mathrm{dl}(<7 \mathrm{mmol} / \mathrm{l})$ [17].

\section{Hypertension}

Individuals diagnosed by a physician and on antihypertensive medications (self-reported) and/or those who had systolic blood pressure $\geq 140 \mathrm{mmHg}$ and/or diastolic blood pressure $\geq 90 \mathrm{mmHg}$-Joint National Committee 8 (JNC8) Criteria [18].

\section{Current smoking}

Smoking in the last one month.

Good glycemic control: defined as fasting blood glucose $<130 \mathrm{mg} / \mathrm{dl}$ [16].

\section{Results}

Sociodemographic and behavioural characteristics

Table 1 shows the socio-demographic, behavioural and clinical characteristics of the respondents in the study. Majority of the respondents are females (64\%), adults in the age group $25-44$ years (51\%), rural residents (61\%) and belong to the general caste (48\%). The prevalence of hypertension among the respondents was $36 \%$. Nearly $15 \%$ were current alcohol users whereas around $4 \%$ were found to be current smokers (Table 1).

\section{Prevalence of DM}

Overall prevalence of DM among the study participants was found out to be $8.3 \%$ (95\% CI 7.3-9.4\%) which was higher in urban areas $(9.4 \%, 95 \%$ CI $7.7-11.4 \%$ ) compared to rural $(7.6,6.4-9.1 \%)$, though not significant. The prevalence of prediabetes was $6.3 \%(5.4-7.3 \%)$ based on ADA criteria and $6.0 \%(5.0-7.1 \%)$ based on NPCDCS 
Table 1 Socio-demographic and behavioural characteristics of the study population, STEPS survey, Punjab, India, 2014-15

\begin{tabular}{|c|c|}
\hline Characteristics & $N=2465(\%)$ \\
\hline \multicolumn{2}{|l|}{ Age group (years) } \\
\hline $18-24$ & $439(18)$ \\
\hline $25-44$ & $1263(51)$ \\
\hline $45-69$ & $763(31)$ \\
\hline \multicolumn{2}{|l|}{ Gender } \\
\hline Male & $890(36)$ \\
\hline Female & $1575(64)$ \\
\hline \multicolumn{2}{|l|}{ Residence } \\
\hline Rural & $1492(61)$ \\
\hline Urban & $973(39)$ \\
\hline \multicolumn{2}{|l|}{ Social group } \\
\hline SC & $926(38)$ \\
\hline Other backward caste & $337(14)$ \\
\hline General & $1163(48)$ \\
\hline \multicolumn{2}{|l|}{ Educational status } \\
\hline Illiterate & $575(23)$ \\
\hline Up to primary education & $575(23)$ \\
\hline Up to secondary education & $365(15)$ \\
\hline Higher education & $950(39)$ \\
\hline \multicolumn{2}{|l|}{ Marital status } \\
\hline Never married & $420(17)$ \\
\hline Currently married & $1834(75)$ \\
\hline Separated/divorced & $31(1)$ \\
\hline Widowed and cohabitating & $162(7)$ \\
\hline \multicolumn{2}{|l|}{ Current smoking } \\
\hline Yes & $104(4)$ \\
\hline No & $2361(96)$ \\
\hline \multicolumn{2}{|l|}{ Current alcohol use $\mathrm{a}^{\mathrm{a}}$} \\
\hline Yes & $381(15)$ \\
\hline No & $2084(85)$ \\
\hline \multicolumn{2}{|l|}{ Hypertension ${ }^{\mathrm{b}}$} \\
\hline Yes & $876(36)$ \\
\hline No & $1589(64)$ \\
\hline
\end{tabular}

a One who has drank alcohol in the past 30 days

b Systolic Blood Pressure $\geq 140$ and/or Diastolic Blood Pressure $\geq 90$ or currently on medication

Figures in parenthesis indicate percentages; SC scheduled caste, SCs are groups of historically disadvantaged people in India recognised by the Constitution of India. Other backward caste is a collective term used by the Constitution of India to classify castes which are socially and educationally disadvantaged although they are considered to be at a less disadvantageous position than SCs and STs; General category is a term used in India to denote a group other than $\mathrm{OBCs}$ and SCs and are considered socially, educationally, and economically advanced

guidelines, again with a higher proportion among the urban dwellers (Table 2). On univariate analysis, the prevalence of DM was found to be significantly higher among those aged 45-69 years (18.0\%), hypertensives (14.3\%), obese (14.4\%), with family history of DM (11.9\%) and those with hypertriglyceridemia. No difference was
Table 2 Prevalence of diabetes and pre-diabetes in Punjab, India stratified by age group, sex, and type of residence, 2014-2015

\begin{tabular}{lcc}
\hline Characteristics & $\begin{array}{l}\text { Prevalence of pre-dia- } \\
\text { betes N (\%, 95\% Cl) }\end{array}$ & $\begin{array}{l}\text { Prevalence } \\
\text { of diabetes N (\%, } \\
\mathbf{9 5 \% ~ C l )}\end{array}$ \\
\hline $\begin{array}{l}\text { Age group (years) } \\
\text { 18-24 }\end{array}$ & $12(2.8,1.6-4.8)$ & $6(1.4,0.6-3.0)$ \\
$25-44$ & $67(5.2,4.1-6.5)$ & $61(4.7,3.7-6.0)$ \\
$45-69$ & $77(9.9,8.0-12.2)$ & $140(18.0,15.5-20.9)$ \\
Sex & & \\
Male & $59(6.5,5.1-8.3)$ & $76(8.4,6.7-10.3)$ \\
Female & $97(6.1,5.0-7.4)$ & $131(8.2,7.0-9.7)$ \\
Type of residence & & \\
$\quad$ Rural & $88(5.8,4.7-7.1)$ & $116(7.6,6.4-9.1)$ \\
Urban & $68(7.0,5.6-8.8)$ & $91(9.4,7.7-11.4)$ \\
Overall & $156(6.3,5.4-7.3)^{\mathrm{a}}$ & $207(8.3,7.3-9.4)$ \\
\hline
\end{tabular}

Diabetes is defined as individuals diagnosed by a physician and/or on antidiabetic medications and/or those who had fasting blood glucose $\geq 126 \mathrm{mg} /$ $\mathrm{dl}$ ( $\geq 7 \mathrm{mmol} / \mathrm{l})$; prediabetes is defined as individuals who had fasting blood glucose $\geq 100 \mathrm{mg} / \mathrm{dl}(\geq 5.6 \mathrm{mmol} / \mathrm{l})$ and $<126 \mathrm{mg} / \mathrm{dl}(<7 \mathrm{mmol} / \mathrm{l})$

a Prevalence of pre-diabetes based on NPCDCS guidelines- fasting blood glucose $\geq 110 \mathrm{mg} / \mathrm{dl}(\geq 6.1 \mathrm{mmol} / \mathrm{l})$ and $<126 \mathrm{mg} / \mathrm{dl}(<7 \mathrm{mmol} / \mathrm{l})$ is $(6.0$, 5.0-7.1) the figures in the parentheses are expressed as percentages with $95 \%$ confidence intervals

found in prevalence by sex, residence, social group, educational status, smoking and alcohol use (Table 3).

\section{Risk factors for DM}

Age group (45-69 years), marital status, hypertension, obesity and family history of DM were found to be the risk factors significantly associated with DM in a multivariate regression model (Table 3).

\section{Treatment and control status of DM}

Among all persons with DM, only 37 (18\%) were known case of DM or on treatment whereas the rest were newly diagnosed. Among those already on treatment or known cases of DM, 13 (35\%) had controlled blood glucose status (Table 4).

\section{Discussion}

Overall prevalence of DM and prediabetes among the study participants was 8.3 and $6.3 \%$ respectively. Only $18 \%$ of all cases of DM were already known case or on treatment, among whom only about one-third had controlled blood glucose status.

This state-wide study was done in one of the most prosperous states in India. There have been few large community based studies looking at prevalence of diabetes in India. The National Urban Diabetes Survey showed an age-standardised prevalence of $12.1 \%$ for diabetes and $14 \%$ for IGT in six large metropolitan cities [5]. The 
Table 3 Socio-economic, behavioural and clinical correlates of patients with diabetes, STEPS survey, Punjab, India, 201415

\begin{tabular}{|c|c|c|c|c|c|c|}
\hline Characteristics & Total & Diabetes & $p$ value & Odds ratio & $95 \% \mathrm{Cl}$ & $\mathrm{p}$ value \\
\hline Age group (years) & & & 0.001 & & & \\
\hline $18-24$ & 430 & $6(1.4)$ & & Ref & & \\
\hline $25-44$ & 1289 & $61(4.7)$ & & 1.5 & $(0.6-3.8)$ & 0.425 \\
\hline $45-69$ & 776 & $140(18.0)$ & & 4.7 & $(1.8-12.4)$ & 0.001 \\
\hline Gender & & & 0.9 & & & \\
\hline Male & 907 & $76(8.4)$ & & - & - & - \\
\hline Female & 1588 & $131(8.2)$ & & - & - & - \\
\hline Residence & & & 0.11 & & & \\
\hline Rural & 1529 & $116(7.6)$ & & Ref & & \\
\hline Urban & 966 & $91(9.4)$ & & 1.1 & $(0.8-1.6)$ & 0.4 \\
\hline Social group & & & 0.053 & & & \\
\hline SC & 954 & $61(6.4)$ & & Ref & & \\
\hline Other backward caste & 342 & $35(10.2)$ & & 1.3 & $(0.8-2.1)$ & 0.3 \\
\hline General & 1155 & $107(9.3)$ & & 1.1 & $(0.8-1.6)$ & 0.6 \\
\hline Educational status & & & 0.07 & & & \\
\hline Illiterate & 575 & $51(8.9)$ & & Ref & & \\
\hline Up to primary education & 599 & $63(10.3)$ & & 1.3 & $(0.8-1.9)$ & 0.2 \\
\hline Up to secondary education & 1065 & $74(6.9)$ & & 1.0 & $(0.6-1.5)$ & 0.9 \\
\hline Higher education & 256 & $19(7.4)$ & & 1.0 & $(0.6-2.0)$ & 0.9 \\
\hline Marital status & & & 0.001 & & & \\
\hline Never married & 413 & $5(1.2)$ & & Ref & & \\
\hline Currently married & 1869 & $172(9.2)$ & & 2.9 & $(1.0-8.1)$ & 0.04 \\
\hline Separated/divorced/widowed & 195 & $29(14.9)$ & & 3.3 & $(1.2-10.0)$ & 0.03 \\
\hline Current smoking & & & 0.7 & & & \\
\hline Yes & 101 & $8(7.9)$ & & - & - & - \\
\hline No & 2394 & $199(8.3)$ & & - & - & - \\
\hline Current alcohol use $\mathrm{a}^{\mathrm{a}}$ & & & 0.109 & & & \\
\hline Yes & 386 & $40(10.4)$ & & - & - & - \\
\hline No & 2109 & $167(7.9)$ & & - & - & - \\
\hline Hypertension ${ }^{b}$ & & & 0.001 & & & \\
\hline Yes & 1031 & $147(14.3)$ & & 2.0 & $(1.4-2.8)$ & 0.001 \\
\hline No & 1464 & $60(4.1)$ & & Ref & & \\
\hline$\geq 5$ servings of fruits and vegetables dailyc & & & 0.4 & & & \\
\hline Yes & 109 & $10(9.2)$ & & - & - & - \\
\hline No & 2386 & $197(8.3)$ & & - & - & - \\
\hline Obesity (Asian cut off) ${ }^{d}$ & & & 0.001 & & & \\
\hline Yes & 1830 & $96(14.4)$ & & 1.6 & $(1.2-2.0)$ & 0.03 \\
\hline No & 665 & $111(6.1)$ & & Ref & & \\
\hline Family history of diabetes & & & 0.001 & & & \\
\hline Yes & 537 & $64(11.9)$ & & 1.4 & $(1.2-1.7)$ & 0.005 \\
\hline No & 1925 & $142(7.4)$ & & Ref & & \\
\hline Family history of raised cholesterol & & & 0.880 & & & \\
\hline Yes & 126 & $11(8.7)$ & & - & - & - \\
\hline No & 2336 & $195(8.3)$ & & - & - & - \\
\hline Family history of high blood pressure & & & 0.965 & & & \\
\hline Yes & 852 & $71(8.3)$ & & - & - & - \\
\hline No & 1610 & 134 (8.4) & & - & - & - \\
\hline
\end{tabular}


Table 3 continued

\begin{tabular}{|c|c|c|c|c|c|c|}
\hline Characteristics & Total & Diabetes & $p$ value & Odds ratio & $95 \% \mathrm{Cl}$ & $p$ value \\
\hline Abdominal obesity ${ }^{e}$ & & & 0.001 & & & \\
\hline Yes & 1415 & $165(11.7)$ & & 1.5 & $(1.1-2.1)$ & 0.01 \\
\hline No & 1080 & $42(3.9)$ & & Ref & & \\
\hline Hypertriglyceridemia $^{f}$ & & & 0.006 & & & \\
\hline Yes & 656 & $136(7.4)$ & & 0.8 & $(0.6-1.1)$ & 0.2 \\
\hline No & 1839 & $71(10.8)$ & & Ref & & \\
\hline \multicolumn{7}{|l|}{ Physical activity ${ }^{9}$} \\
\hline Above minimal recommended & 140 & $04(3.0)$ & 0.008 & Ref & & \\
\hline Below minimal recommended & 2355 & $203(8.6)$ & & 1.8 & $1.5-2.1$ & 0.01 \\
\hline
\end{tabular}

Cl confidence interval, SC scheduled caste

a One who has drank alcohol in the past 30 days

b $\mathrm{SBP} \geq 140$ and/or DBP $\geq 90$ or currently on medication

c One serving of vegetable was considered to be one cup of raw green leafy vegetables or $1 / 2$ cup of other vegetables (cooked or chopped raw). One serving of fruit was considered to be one medium size piece of apple, banana or orange, 1/2 cup of chopped, canned fruit or $1 / 2$ cup of fruit juice

d Body mass index $\geq 27.5 \mathrm{~kg} / \mathrm{m}^{2}$

e $\geq 90 \mathrm{~cm}$ for males and $\geq 80 \mathrm{~cm}$ for females

f Serum triglyceride $>150 \mathrm{mg} / \mathrm{dl}$

9 Minimum duration of physical activity per week recommended by WHO as 150 min of moderate intensity physical activity or 75 min of vigorous intensity physical activity or an equivalent combination of moderate- and vigorous-intensity physical activity achieving at least 600 MET-minutes per week with each activity performed in bouts of at least 10-min duration; Backward conditional multivariate logistic regression was performed and values are presented as odds ratio with $95 \%$ confidence interval and $p$ value

Table 4 Treatment and control status among diabetic patients in Punjab, STEPS survey, 2014-15

\begin{tabular}{llll}
\hline $\begin{array}{l}\text { Demographic } \\
\text { variables }\end{array}$ & Total diabetics N & $\begin{array}{l}\text { On treatment } \\
\mathbf{N}(\%)\end{array}$ & $\begin{array}{l}\text { Good glyce- } \\
\text { mic controlN } \\
(\%)\end{array}$ \\
\hline $\begin{array}{l}\text { Total } \\
\text { Gender }\end{array}$ & $\mathrm{N}=207$ & $\mathrm{~N}=37(18)$ & $\mathrm{N}=13(35)$ \\
Male & 76 & $16(21)$ & $6(38)$ \\
Female & 131 & $21(16)$ & $7(33)$ \\
Age (in years) & & $2(33)$ & $2(100)$ \\
$18-24$ & 6 & $12(20)$ & $4(33)$ \\
$25-44$ & 61 & $23(16)$ & $7(30)$ \\
$45-69$ & 140 & & $9(41)$ \\
Residence & & $22(19)$ & $4(27)$ \\
Rural & 116 & $15(16)$ & \\
Urban & 91 &
\end{tabular}

Good glycemic control is defined as fasting blood glucose $<130 \mathrm{mg} / \mathrm{dl}$

Prevalence of Diabetes in India Study (PODIS) reported lower diabetes prevalence of 5.9 and $2.7 \%$ in urban and rural areas respectively with an overall prevalence of 4.3\% [19]. Two studies in Chandigarh, a very prosperous city in North India, showed high prevalence of diabetes. In the INDIAB study, the city was found to have the highest prevalence of diabetes (13.6\%) [3]. The Chandigarh Urban Diabetes Survey (CUDS) also reported high prevalence of diabetes and prediabetes i.e. 11.1 and $13.2 \%$ respectively [9].
Barik et al. in a large cross-sectional survey in rural West Bengal, which is situated in the eastern region of the country, found that the prevalence of diabetes and pre-diabetes among adults $>18$ years was 2.95 and $3.34 \%$ respectively [6]. In another study, Little et al. reported a high prevalence of type 2 diabetes (10.8\%) among adults population ( $>19$ years) in rural parts of South India [4]. These figures imply that though the prevalence of DM varies in different settings, it is certainly quite high and warrants immediate attention.

Our study adds to the limited but growing body of evidence suggesting that diabetes is no longer confined to urban areas of India and is a matter of concern in rural areas as well [4]. Considering the fact that over $70 \%$ of the population of India are rural and often faced with issues like poverty, poor access to health care, this is quite a worrisome finding. The present study reported no gender difference in the prevalence of DM which is supported by evidence from other studies in India $[5,6$, 20], although a few studies have shown a male preponderance $[3,21]$.

Generalized obesity/high BMI and abdominal obesity were independently associated with diabetes which is similar to the results in most other studies [3-6, 9, 21]. Indians have a lower BMI than those of European descent. However, the risk of diabetes increases at very low levels of BMI for Indians [22]. Poor physical activity was also associated with diabetes as supported by earlier studies $[4,6]$. The protective effects of physical activity against 
obesity, cardiovascular disease, and metabolic syndrome have already been proven [23]. The associations remained even after controlling for anthropometric measures, indicating that physical activity may have a direct impact on risk of diabetes apart from its association through obesity $[4,24]$. Efforts that focus on healthy diet and promoting physical activity have the potential to reduce the risk of obesity, the single most important risk factor for type 2 diabetes [6]. Family history of DM is a strong predictor of the disease which is supported by most other studies $[3,5,9]$. The study results indicate that elderly individuals, hypertensives, obese (general/abdominal) or those with a family history of DM constitute an important group for screening.

Nearly $80 \%$ of individuals with diabetes were previously undiagnosed. The ratio of undiagnosed to total patients with DM was much higher compared to another study in rural Tamil Nadu conducted by Anjana et al. (48\% undiagnosed) [3]. In another study in Delhi, only one-third of the diabetic patents were aware of their condition [25] thereby indicating the need for aggressive screening programs. Despite screening for NCDs including diabetes being a major component of the National Programme for Control of Cancer, Diabetes, Cardiovascular Diseases and Stroke (NPCDCS) in India, implementation is dismal [26]. The government of India has taken certain initiatives at national level which is appreciable, but there is a need to implement it at grass root level before the disease takes the shape of a pandemic in India. The pool of undiagnosed cases of DM left untreated is more prone to microvascular as well as macrovascular complications. Hence, it is necessary to identify and offer early therapy to these individuals and ensure regular follow up. The study results show that among persons with known DM on treatment, nearly two-third had uncontrolled blood glucose levels. Further studies are required to understand the reasons for the same.

The strengths of the study include a large multistage stratified community based sample, high participant response rate, use of standardized STEPS questionnaire and robust methodology and adherence to STROBE reporting guidelines [27].

\section{Study limitations}

The study had few limitations. Firstly, this being a crosssectional study, prevents us from drawing causal inferences. Secondly, measurement of blood glucose was done by a glucometer device instead of venous blood glucose estimation due to logistic constraints. However, regular quality control check on blood glucose measurement was done in a reference laboratory as per the manufacturer's instructions. Thirdly, only fasting blood glucose was used to diagnose diabetes and pre-diabetes.

\section{Conclusion}

In conclusion, the present study provides reliable and recent epidemiological information regarding the high burden of diabetes mellitus among the adult population in a representative North Indian population. Around $15 \%$ of the general adult population have diabetes or pre-diabetes, calling for an urgent attention. This study also highlights a significant burden of undiagnosed cases of DM in the community, most of them are poorly controlled. There is need to identify the large pool of undiagnosed cases of DM and offer early treatment in order to avoid complications.

\section{Abbreviations \\ NCD: non communicable disease; DM: diabetes mellitus; LDL: low density lipoproteins; HDL: high density lipoproteins; GPAQ: Global Physical Activity Questionnaire; BMI: body mass index. \\ Authors' contributions \\ JPT, JST and GB were responsible for preparation of study proposal, study tool, data collection, interpretation of data and preparation and editing of the manuscript. SC was involved in data collection, entry and analysis. SJ, AP, RK and RS were responsible for preparation of study tool, data collection, data analysis and editing of the manuscript. All the authors critically reviewed the paper and approved the final draft for submission. All authors read and approved the final manuscript.}

\section{Author details}

${ }^{1}$ International Union Against Tuberculosis and Lung Disease, The Union South East Asia Office, New Delhi, India. ${ }^{2}$ School of Public Health, Post Graduate Institute of Medical Education and Research, Chandigarh, India. ${ }^{3}$ Department of Internal Medicine, Post Graduate Institute of Medical Education and Research, Chandigarh, India. ${ }^{4}$ Department of Biochemistry, Post Graduate Institute of Medical Education and Research, Chandigarh, India. ${ }^{5}$ Department of Internal Medicine and Epidemiology, University of Michigan, Ann Arbor, MI, USA.

\section{Acknowledgements}

We acknowledge the Department of Health and Family Welfare of Punjab state for granting responsibility of conducting the NCD Risk Factors Survey in Punjab and funding this project through National Health Mission (NHM). We also sincerely acknowledge the support received from National Health Mission, Ministry of Health and Family Welfare, Government of India and World Health Organization. We also thank the Department for International Development (DFID), UK, for funding the Global Operational Research Fellowship Programme at the International Union Against Tuberculosis and Lung Disease (The Union), Paris, France in which Jaya Prasad Tripathy works as an Operational Research Fellow.

\section{Competing interests}

The authors declare that they have no competing interests.

\section{Availability of data}

Data are not available in public domain because they are currently being analysed in related papers. However, data are available with the corresponding author (JST) and will be made accessible on request at the following e-mail: jsthakur64@gmailcom.

\section{Ethics}

Ethics approval was obtained from the Institute Ethics Committee, Post Graduate Institute of Medical Education and Research, Chandigarh, India (reference number P-727, dated July 21, 2014). Written informed consent was obtained from the participants.

\section{Funding}

This project was funded by the National Health Mission, Punjab, India. We thank Department for International Development (DFID), UK and La Fondation 
Veuve Emile Metz-Tesch (Luxembourg), for funding this open access publication.

Received: 1 October 2016 Accepted: 13 January 2017

Published online: 23 January 2017

\section{References}

1. International Diabetes Federation. IDF Diabetic Atlas 7th Edition. http:// www.idf.org/idf-diabetes-atlas-seventh-edition. Accessed 30 Aug 2016.

2. Hwang CK, Han PV, Zabetian A, Ali MK, Narayan KMV. Rural diabetes prevalence quintuples over twenty-five years in low- and middle-income countries: a systematic review and meta-analysis. Diabetes Res Clin Pract. 2012;96(3):271-85.

3. Anjana RM, Pradeepa R, Deepa M, Datta M, Sudha V, Unnikrishnan R, et al. Prevalence of diabetes and prediabetes (impaired fasting glucose and/ or impaired glucose tolerance) in urban and rural India: phase I results of the Indian Council of Medical Research-INdia DIABetes (ICMR-INDIAB) study. Diabetologia. 2011;54(12):3022-7.

4. Little M, Humphries S, Patel K, Dodd W, Dewey C. Factors associated with glucose tolerance, pre-diabetes, and type 2 diabetes in a rural community of south India: a cross-sectional study. Diabetol Metab Syndr. 2016:8:21.

5. Ramachandran A, Snehalatha C, Kapur A, Vijay V, Mohan V, Das AK, et al. High prevalence of diabetes and impaired glucose tolerance in India: National Urban Diabetes Survey. Diabetologia. 2001;44(9):1094-101.

6. Barik A, Mazumdar S, Chowdhury A, Rai RK. Physiological and behavioral risk factors of type 2 diabetes mellitus in rural India. BMJ Open Diabetes Res Care. 2016;4(1):e000255.

7. Ajay VS, Prabhakaran D, Jeemon P, Thankappan KR, Mohan V, Ramakrishnan $L$, et al. Prevalence and determinants of diabetes mellitus in the Indian industrial population. Diabet Med. 2008;25(10):1187-94.

8. Mohan V, Deepa M, Deepa R, Shanthirani CS, Farooq S, Ganesan A, et al. Secular trends in the prevalence of diabetes and impaired glucose tolerance in urban South India-the Chennai Urban Rural Epidemiology Study (CURES-17). Diabetologia. 2006:49(6):1175-8.

9. Ravikumar P, Bhansali A, Ravikiran M, Bhansali S, Walia R, Shanmugasundar $\mathrm{G}$, et al. Prevalence and risk factors of diabetes in a community-based study in North India: the Chandigarh Urban Diabetes Study (CUDS). Diabetes Metab. 2011;37(3):216-21.

10. Mendenhall E, Shivashankar R, Tandon N, Ali MK, Narayan KMV, Prabhakaran D. Stress and diabetes in socioeconomic context: a qualitative study of urban Indians. Soc Sci Med. 2012;75(12):2522-9.

11. Mohan V. Why are Indians more prone to diabetes? J Assoc Physicians India. 2004:52:468-74.

12. Suryanarayana M, Agrawal A, Prabhu K. Inequality-adjusted human development index for India's States. New Delhi; 2011.

13. Thakur JS, Jeet G, Pal A, Singh S, Singh A, Deepti SS, et al. Profile of Risk Factors for Non-Communicable Diseases in Punjab, Northern India: results of a State-Wide STEPS Survey. PLOS ONE. 2016;11(7):e0157705.

14. World Health Organization. The WHO STEPwise approach to Surveillance of noncommunicable diseases (STEPS). Geneva: World Health Organization; 2003. http://www.who.int/ncd_surveillance/en/steps_framework_ dec03.pdf. Accessed 30 Aug 2016.

15. World Health Organization. Global Physical Activity Questionnaire (GPAQ) analysis guide. Geneva: World Health Organization; 2012. http://www. who.int/chp/steps/resources/GPAQ Analysis Guide.pdf.

16. American Diabetes Association. Standards of medical care in diabetes-2016. Diabetes Care. 2016;39(Suppl 1):S13-22.

17. Directorate General Health Services Ministry of Health and Family Welfare. National Programme for prevention and control of Cancer, Diabetes, Cardiovascular Diseases \& Stroke Operational Guidlines (2013-17). New Delhi; 2013.

18. James PA, Oparil S, Carter BL, Cushman WC, Dennison-Himmelfarb C, Handler J, et al. 2014 evidence-based guideline for the management of high blood pressure in adults: report from the panel members appointed to the Eighth Joint National Committee (JNC 8). JAMA. 2014;311(5):507-20.
19. Sadikot SM, Nigam A, Das S, Bajaj S, Zargar AH, Prasannakumar KM, et al. The burden of diabetes and impaired glucose tolerance in India using the WHO 1999 criteria: prevalence of diabetes in India study (PODIS). Diabetes Res Clin Pract. 2004;66(3):301-7.

20. Goswami AK, Gupta SK, Kalaivani M, Nongkynrih B, Pandav CS. Burden of hypertension and diabetes among urban population aged $\geq 60$ years in South Delhi: a community based study. J Clin Diagn Res. 2016;10(3):LC01-5.

21. Meshram II, Vishnu Vardhana Rao M, Sudershan Rao V, Laxmaiah A, Polasa K. Regional variation in the prevalence of overweight/obesity, hypertension and diabetes and their correlates among the adult rural population in India. Br J Nutr. 2016;115(7):1265-72.

22. Chan JCN, MalikV, Jia W, Kadowaki T, Yajnik CS, Yoon K-H, et al. Diabetes in Asia: epidemiology, risk factors, and pathophysiology. JAMA. 2009;301(20):2129-40.

23. Kesaniemi YK, Danforth E, Jensen MD, Kopelman PG, Lefèbvre P, Reeder $B A$. Dose-response issues concerning physical activity and health: an evidence-based symposium. Med Sci Sports Exerc. 2001;33(6 Suppl):S351-8.

24. Little M, Humphries S, Patel K, Dewey C. Factors associated with BMI, underweight, overweight, and obesity among adults in a population of rural south India: a cross-sectional study. BMC Obes. 2016;3:12.

25. Singh AK, Mani K, Krishnan A, Aggarwal P, Gupta SK. Prevalence, awareness, treatment and control of diabetes among elderly persons in an urban slum of Delhi. Indian J Community Med. 2012;37(4):236-9.

26. Chauhan G, Thakur J. Assessing health workers' capacity for the prevention and control of noncommunicable diseases in Haroli health block of district Una in Himachal Pradesh, India: a mixed methods approach. Int J Noncommunicable Dis. 2016;1(1):26.

27. von Elm E, Altman DG, Egger M, Pocock SJ, Gøtzsche PC, Vandenbroucke JP, et al. The Strengthening the Reporting of Observational Studies in Epidemiology (STROBE) statement: guidelines for reporting observational studies. Bull World Health Organ. 2007;85(11):867-72.

\section{Submit your next manuscript to BioMed Central and we will help you at every step:}

- We accept pre-submission inquiries

- Our selector tool helps you to find the most relevant journal

- We provide round the clock customer support

- Convenient online submission

- Thorough peer review

- Inclusion in PubMed and all major indexing services

- Maximum visibility for your research

Submit your manuscript at www.biomedcentral.com/submit 